\title{
Ladd AP, Rescorla FJ, Grosfeld JL (Eds.): Handbook of pediatric surgical patient care
}

\author{
World Scientific Publishing Co. Pte Ltd
}

\author{
Michael E. Höllwarth
}

Published online: 8 August 2014

(C) Springer-Verlag Berlin Heidelberg 2014

The new multi-author Handbook of Pediatric Surgical Patient Care is edited by some of the internationally most recognized pediatric surgeons, Allan Ladd, Frederick Rescorla and Jay Grosfeld. It is focused on the decisionmaking process in the management of pediatric surgical patients and is aimed to provide guidelines for diagnosis. The soft cover book with nearly 1,000 pages is divided into 11 sections with 87 chapters covering a wide range of topics on all aspects of pediatric surgery.

The first section is focused on physiological aspect of the neonate and child and describes in several chapters the pre- and postoperative requirements for successful surgical therapy. The next three sections concentrate on trauma, tumors and transplantation. The three following sections are divided according to the anatomical regions into neck anomalies, thoracic and abdominal surgical problems. Other sections cover liver and pancreas disorders, urologic problems, and vascular anomalies. The last section is focused on special problems such as congenital heart diseases, neurosurgical considerations, orthopedic deformities and problems with central venous lines and soft tissue infections.
The writing style is uniform and direct. Functional and organic disorders in pediatric surgery are touched in a clear and balanced fashion. Many, but unfortunately not all chapters, have excellent drawings and radiographic or ultrasound images. The majority of chapters have a good selection of references at the end for readers who wish to explore a topic of special interest in more detail. My only criticism is that the depth and breadth of some chapters are patchy. For example, the chapters on gastroesophageal reflux as well as on gastrostomy are quite short, without any figures and references. These chapters are in clear contrast to others providing excellent figures and up-todate references.

Bottom line: The book is soft cover and portable, although it does not fit into a doctor's coat pocket. Medical students, pediatricians and practitioners caring for infants and children will find this book quite useful providing a brief, excellent and easily accessible source of the state of the art in pediatric surgery. 